\title{
THE LEGAL GUIDELINE FOR ORGAN TRANSPLANTATION AND THERAPEUTIC TISSUE REMOVAL
}

Rahman KGM ${ }^{1}$, Osman $\mathrm{MK}^{2}$, Mahmud $\mathrm{S}^{3}$, Rahman $\mathrm{MM}^{4}$

\begin{abstract}
:
Organ transplantations have caused profound changes in saving the life in current days. Also raised several questions in the legal and ethical ground.

In this paper we discussed legal considerations, donation procedures, death determination, diagnosis of brain death and organ transplantation act of Bangladesh.
\end{abstract}

Key words: Legal guideline, organ transplantation, therapeutic tissue removal.

\section{Introduction:}

Organ transplantation has leapt into prominence in recent years due to technical advances. This has raised many problems not only medical and legal but also ethical and even religious. The public reaction to the subject is very labile and sensitive. Some forms of tissue transplantation are long established and arouse no passions. amongst the majority of the public, though certain religious sectors still objects. Blood transfusion is the oldest practical form of tissue transplantation but the Jehovah's Witnesses refuse blood transfusion based on Bible doctrine in the Old Testament "Firmly resolved not to eat blood, because the blood is the soul and you must not eat the soul

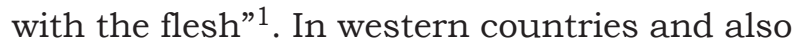
in all over the world the donors are giving and suffer no ill effects, no antipathy is aroused in blood transfusion. More recently bone marrow transplantation has been developed but again as an easily regenerated tissue, it posses no ethical or legal problems. Corneal grafting is another technique where, because the controversy about the definition of death in the donor is not relevant, only emotive feelings about disfigurement from removal of the eyes complicate the issue ${ }^{1}$.
First statute law on tissue transplantation was implemented because of corneal transplants, the corneal grafting Act of 1952, it is the forerunner of the more comprehensive"Human tissue Act of 1961". This Act controls present legal requirements, though its drafting leaves certain matters undecided and new legislation is required to certify some ambiguities \& omissions ${ }^{2}$. Different country adopt different laws regarding organ transplantation depending on their social, cultural \& religious back ground.

This article discussed some of the medical, legal and ethical issues regarding the legal guideline for organ transplantation and therapeutic tissue removal.

\section{Legal and ethical considerations in the transplantation:}

The type of tissue required for transplantation makes a profound difference to legal and ethical consideration ${ }^{3}$. For example where blood transfusion is concerned, no problem arise at all except in some religious sectors, who objects any form of transplantation as mentioned before. With corneal grafting, artery grafting, the problems are relatively minor, because these tissues may be removed many hours after death.

1. Assistant Professor. Forensic Medicine Department. Dhaka Medical College, Dhaka.

2. Assistant Professor. Forensic Medicine Department. Pabna Medical College, Pabna.

3. Lecturer, Forensic Medicine Department. Dhaka Medical College, Dhaka.

4. Assistant Professor. Forensic Medicine Department. Rajshahi Medical College, Rajshahi.

Correspondence: Dr. Kazi Golam Mukhlesur Rahman 
In the recent technical advances in organ transplantation that have caused profound changes in the legal and ethical considerations surrounding the donation of tissues ${ }^{2,4}$. The most common organ to be transplanted is the kidney with the greatest record of success. The same questions arise in connection with other organs, notably the heart, lungs, liver and pancreas.

\section{Donation procedures:}

For organ transplantation which includes kidney, heart, liver., pancreas, lungs-etc, the organ must either be removed while the circulation is still functioning or removed within a very short time of cardiac arrest, to reduce the warm ischemic time to a minimum. With kidneys, it was the former practice to switch off mechanical ventilation and wait for the heart to stop before removing kidney but this method reduced the success rate of transplantation by a significant percentage ${ }^{5}$. Thus all organs are now removed while the heart is still beating and the tissues perfused with oxygenated blood. This forms the most controversial aspect of donation as the moment of death is then a more arbitrary point in time.

\section{The choice of donor:}

An organ donor must be:

a) Deeply and irreversibly unconscious.

b) Without spontaneous respiration, thus sustained on artificial ventilation.i,e, must be in intensive care unit.

c) Must be shown to have irreversible brain stem death.

Person with systemic infections, tumors other than primary brain neoplasms, renal disease and severe atherosclerosis are unsuitable for organ donation. These criteria do not necessarily apply to corneal donors ${ }^{1.2}$.

The prerequisites for removal of organs from live donors:

a) A full explanation of the procedure involved must be given to the donor. b) The possible consequences and risks being fully explained.

c) If these risks are accepted, a written witnessed consent must be obtained.

d) Advised to consult with family advisers.

The use of organs from related live donors is attended by a greater success rate than with the use of cadaver tissues. Patients receiving such a live organ will have a $93 \%$ chance of surviving a year, compared with an $82 \%$ chance with a cadaver donation ${ }^{2}$.

The pre requisites for removal of organs from dead donors:

a) The organ donor has given his consent.

b) The death of the organ donor has been declared according to rules reflecting the Government decision.

c) The intervention is preformed by a physician $^{1,2}$.

\section{Determination of death:}

Formerly, Cessation of respiration and circulation were the criteria for determining death. As all potential donors will of necessity be on artificial ventilation and circulation, must be present for the donor tissue to be viable, then some other criterion must be sought, this is brain stem death. Once death has been diagnosed, then there is no legal objection to drugs being given where necessary to maintain the condition of the organs ${ }^{1,2}$.

\section{Diagnosis of brain death:}

1) Conception of death ascertainment: Attribution : Coordination to the subject of death e.g. human being, organism, person.

Definition : Cessation of personal existence. Irreversible functional loss of the organism.

Criteria : Functional loss of cerebrum, brain stem, the whole brain, indicates death.

Tests : Methods for fulfilling the criterias, clinical examination. ECG etc ${ }^{7}$. 
2) Criteria of brain death :

Precondition : (a) Acute severe primary or secondary brain damage.

(b) Exclusion of intoxication, hypothermia, Circulatory shock, metabolic or endocrinic coma.

Clinical findings: Unconsciousness.

(b) Non reacting medium sized up to maximum dilated pupils (Without mydriatics).

(c) Absence of occulocephalic reflex e.g, corneal reflex, Pain reaction in trigeminal area, Pharyngeal reflex.

(d) Absence of spontaneous breathing.

Complementary Examination :

(a) Electro cerebral inactivity

(b) Cessation of evoked potentials $^{8}$.

Diagnostic tests for brain stem death:

(a) All brain stem reflexes are absent.

(b) Fixed pupils, unresponsive to light.

(c) Absent corneal reflexes.

(d) Absent vestibule-ocular reflexes( ice-water in ears)

(e) No motor responses in cranial nerves.

(f) No gag reflex to catheter in trachea.

(g) No respiratory movements when patient disconnected from ventilator 5 .

The test should be repeated by two doctors to ensure permanent absence of response. The interval is variable between tests but may be up to 24 hours in equivocal cases ${ }^{6}$.
The persistence of spinal reflexes is not relevant in the diagnosis of brain stem death. The use of electroencephalography is not essential for the diagnosis, neither is central angiography nor measurements of cerebral blood flow.

Testing should be carried out at a body temperature not less than $35^{\circ} \mathrm{c}$, as hypothermia may itself mimic brain stem damage.

\section{The Human organ Transplantation Act (UK)} in short:

1) Prohibit any payment for donated organs for transplantation or any negotiation or advertising for this purpose.

2) The removal or transplantation of any organ or tissue from a living person unless they are genetically related within certain fixed limits. Regulations were made to establish the serological tests required to determine the genetic relationship.

3) A regulatory authority has been set up, while must give permission to doctors who wish to transplant from live donors who are not within the prescribed limits of genetic relationship.

4) Regulations about obtained proper informed consent from the donors were established and anew registration system of all transplants was based upon the south western regional health authority as the national registration center ${ }^{1}$.

\section{Organ Transplantation act (Bangladesh) 1999 in Short:}

Government feels to ensure legal procedure for collection, Preservation and lawful use of human organs.

The Act
A. Title :- Human organ transplantation act 1999
B. Definition :- If not otherwise declared
a) "ORGAN" means kidney, heart, Liver, pancreas, bones, bone-marrow, eye, skin and tissues required for transplantation.


b) 'Legal successor' means, husband, wife, Adult son-daughter, Father,

Mother, Brother, Sister and blood related any other relation.

c) 'Close relations' means Son, Daughter, Father, Mother, Brother, Sister,

Blood related uncle, aunt, husband, wife.

d) 'Brain Death' brain death can be declared by any of the following three physicians-

Professor or associate professor.

Assistant Professor or equivalent doctor.

Consultant or equivalent doctor.

Conditions for declaring brain death-

i. Person in coma with known cause not less than 12 hours.

ii. Curable causes of coma should be corrected before 12 hours coma.

iii. Absence of natural respiration, respiration should be continued by ventilator.

iv. Brain stem reflexes should be completely absent.

Other means for declaring brain death-

i. EEG and angiogram of brain.

ii. Apnoea test.

C. Conditions for organ donation :-

a) Age not less than 2 years, not more than 65 years.

b) Reliable causes should be present for damage of the organ.

D. Conditions for transplantation:-

a) Age should be 02-70 years.

b) Diseases should be excluded before transplantation.

c) Medical board should declare.

E. Medical board :-

Board should be constituted by-

i) One professor or Associate professor.

ii) One Assistant professor or equivalent.

iii) One consultant or equivalent.

F. Conditions for donation by living Person :-

a. Any person's organ, that will not hamper his life after taking that organ. b. Any person not carrying such diseases that can be transmitted to the recipient.

G. Conditions for collection of organ from dead body :-

a. if he declared before death for donation.

b. If no body claim that dead body within 24 hours of death.

H. Buying and selling of organs completely prohibited.

I. If any one breaks this act will be punished by 3-7 years rigorous imprisonment.

J. This act only be changed by the Govt. of the Peoples Republic of Bangladesh ${ }^{9}$.

\section{Conclusion:}

Organ transplantation is one of the modern treatments for savings life. Though there is controversy in different religious person yet majority were accepted. It is very much essential to know the legal guideline of organ transplantation \& therapeutic tissue removal for clinical application in our day to day practice.

\section{References:}

1. Bernard knight. Legal aspects of medical practice. $5^{\text {th }}$ edition. Churchill Livingstone. Edinburgh London Madrid Melbourne New York and Tokyo. 1992 P-47-57.

2. The methodology of determing brain death-M. Staak, proceeding of Advances in legal Medicine3 Osaka, Japan. legal Med.3(1997).

3. Dr. K.S. Narayan Reddy. The essentials of Forensic Medicines \& Toxicology. 27 $7^{\text {th }}$ edition, 2008. K.Sunguna Devi, Hyderabad. P-120.

4. Principles of Forensic Medicine. Apurba Nandy. $1^{\text {st }}$ edition-1995. New central book Agency (p) Ltd. P-133.

5. Bernard knight. Simson's Forensic Medicine. $11^{\text {th }}$ edition. Arnold. London, Sydney, Auckland. P10-11.

6. Parikh CK. Parikh's text book of Medical Jurisprudence and toxicology. $4^{\text {th }}$ edition 1986.CBS Publisher's \& distributors.

7. Organ donation-How Acceptable it is in Philippine-Proceeding of INPALMS 1998-Kobe.

8. Forensic Medical experiences concerning quality standards of cornea explantation/ Transplantation-K. Pasdchel, J. Gerepp. proceeding of advances in legal medicine-3 Osaka, Japan.

9. The Bangladesh Gazette, April $13^{\text {th }} 1999$. 